\title{
IOT ENABLED SMART AND SECURE INDUSTRY POLLUTION MONITORING AND CONTOLLING SYSTEM
}

\author{
Aravindraj R \\ Department of Electronic and Communication, \\ Dhanalakshmi Srinivasan Institute of Technology, \\ Samayapuram, Trichy, Tamil Nadu, India, \\ Arun Mozhi Varamban B \\ Department of Electronic and Communication, \\ Dhanalakshmi Srinivasan Institute of Technology, \\ Samayapuram, Trichy, Tamil Nadu, India,
}

\begin{abstract}
Nowadays most of the pollution monitoring systems are widely used in industries. The industrial parameters which causes pollution in the natural and industrial environment pattern. The main aim of our project is to control the parameters causing pollution and to reduce the effect of these parameters without affecting the natural or industrial environment. The proposed technique is to design an efficient system to read and monitor pollution parameters and if any of these factors exceeds the industry standards, immediately these information send to pollution control authority by using IOT methodology. Which will automatically monitor, if any of these parameters affects the system. And also these parameters can be monitor in PC. These systems find the amount of $\mathrm{pH}$ present in the industry, level of smoke released, machineries temperature and noise in the industrial environment during industrial process. Thus through our project we will try to monitor and control of pollution efficiently and the data can be transferred through internet. Cayenne is a graphical user interface to the user and IOT is used for outside world interaction for information transfer.
\end{abstract}

Keywords - Industry pollution control, IOT based System, PIC controller, sensors, cloud backup.

\section{INTRODUCTION}

A BSN (Body Sensor Network) is a network designed to operate autonomously to connect the various medical sensors and implants located inside and/or outside of the human body; which offers flexible operation and cost saving options to both healthcare professionals and patients. This work illustrates the design and implementation of a smart health monitoring system communications standards, and cloud technologies.

\author{
Haresh Gokilan E \\ Department of Electronic and Communication, \\ Dhanalakshmi Srinivasan Institute of Technology, \\ Samayapuram, Trichy, Tamil Nadu, India, \\ Jagadeesan M \\ Department of Electronic and Communication, \\ Dhanalakshmi Srinivasan Institute of Technology, \\ Samayapuram, Trichy, Tamil Nadu, India,
}

The terms monitoring and assessment are frequently confused and used synonymously. The process of industrial quality assessment is an evaluation of the industrial quality in relation to standard quality set by pollution control board. Particular attention is given to factors which may affect human health and the health of the natural system itself. Environmental quality assessment includes the use of monitoring to define the condition of the water, to provide the basis for detecting trends and to provide the information enabling the establishment of cause effective relationships. Industrial quality monitoring is the collection of information at set locations of different industries and at regular intervals in order to provide the data which may be used to define current conditions, establish trends etc. Due to the complexity of factors determining industrial quality, large variations are found between different industries. Similarly, the response to industrial impacts is also highly variable. The main reason for the assessment of the quality of the industrial environment has been, traditionally, the need to verify whether the observed industrial quality is suitable for intended uses[2]. The use of monitoring has also evolved to determine trends in the quality of the water, air and soil environment and how they are affected by the release of contaminants, other anthropogenic activities, and/or by waste treatment operation (impact monitoring). More recently, monitoring has been undertaken to estimate nutrient or pollutant fluxes discharged to rivers, ground waters, lakes, oceans and soil or across international the boundaries. The assessment of background quality of the industrial environment is also now widely undertaken as it provides a means of comparison with impact monitoring. It is also used simply to check whether any unexpected change is occurring in otherwise pristine pollutants. However, it should be noted that industrial environmental quality is very variable depending on local conditions. Fresh water is a finite resource essential for use in agriculture, industry, propagation of 


\section{International Journal of Engineering Applied Sciences and Technology, 2020 \\ Vol. 4, Issue 10, ISSN No. 2455-2143, Pages 321-327 \\ Published Online February 2020 in IJEAST (http://www.ijeast.com)}

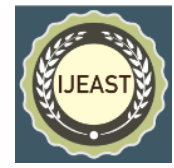

wildlife \& fisheries and for human existence. India is a riverine country. It has 14 major rivers, 44 medium rivers and 55 minor rivers besides numerous lakes, ponds and wells which are used as primary source of drinking water even without treatment.

As we probably are aware the mechanical development radically expanding, natural contamination related issues quickly appears To satisfy the need of thriving observing framework, in our task we are setting up a system called Internet of Things, in which detecting gadgets are associated with remote implanted processing framework. Web of Things is an innovation that connects the sensors with installed framework and enables the information from these sensors to go over an Internet. We are actualizing creating model which can screens the capriciousness of parameter like Air, Noise, Temperature. Most of the rivers being fed by monsoon rains, which are limited to only three months of the year, run dry throughout the rest of the year often carrying wastewater discharges from industries or cities or towns endangering the quality of our scarce water resources. Similarly working environment in an industry is important for safety of its workers and people who live near to it. Hence it is important to monitor amount of temperature and carbon monoxide level in an industry. The main problem faced in previous papers where either the process was complex or it required high cost for implementation. Also other processes mainly lacked access at remote locations and hence this system proves to overcome these major drawbacks. The main objectives of Industrial pollution monitoring system using IOT[1].

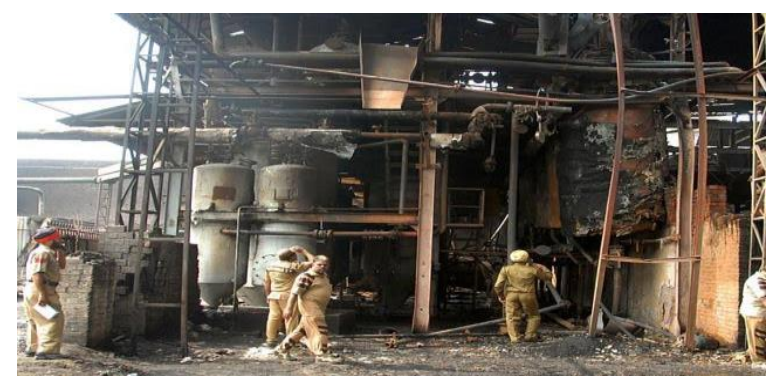

Fig 1: Workers Working In Polluted Environment

To build a robust system that can measure the industrial pollution and help to reduce it and to decrease human interference in monitoring the industrial pollution to reduce pollution and provide a healthy environment for the workers to work in. To make the industrial pollution monitoring \& control with wireless system. To protect the environment from industrial pollution. To build a robust system that evaluates the industrial pollution continuously and indicates when there is an increase in the emissions and takes action to control it.

\section{SOURCE OF POLLUTANTS}

In recent years, the rapid industrialization across various parts of asia (particularly in India and China )has been a boon to the economics. unfortunately, the rise in industrialization and the standard of living are coupled with poor implementation of governmental rules and regulation, which results in increased concentration of many pollutants. The pollutants are harmful to living beings and the envinroment if exposed beyond perimissible exposure limits (PEL) published by the occupational safety and health administration(OSHA).

\section{CURRENT PH SENSOR,TEMPERATURE SENSOR,GAS SENSOR,NOISE SENSOR}

Here we are using pH Sensor just as you would a traditional $\mathrm{pH}$ meter with the additional advantages of automated data collection, graphing, and data analysis. Typical activities using our $\mathrm{pH}$ sensor include; Acid-base titrations, Studies of household acids and bases, Monitoring $\mathrm{pH}$ change during chemical reactions or in an aquarium as a result of photosynthesis, Investigations of acid rain and buffering, Analysis of water quality in streams and lakes. A $\mathrm{pH}$ sensor is a device that measures the hydrogen-ion concentration $(\mathrm{pH})$ in a solution, indicating its acidity or alkalinity .In addition to measuring the $\mathrm{pH}$ of liquids, it can also measure the moist and light level. The $\mathrm{pH}$ sensor has an inbuilt meter to measure the light intensity[5]. The $\mathrm{pH}$ sensor is connected with a board to get a digital input.

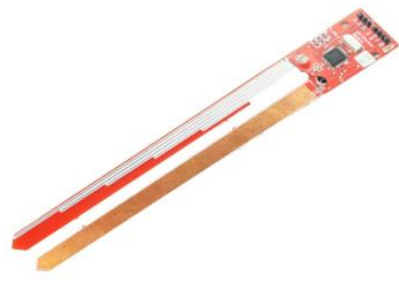

Fig1.1: PH Meter

$\mathrm{A} \mathrm{pH}$ meter is a scientific instrument that measures the hydrogen-ion activity in water-based solution, indicating its acidity or alkalinity expressed as ph. The $\mathrm{pH}$ meter measures the difference in electrical potential between a $\mathrm{pH}$ electrode and a reference electrode, and so the $\mathrm{pH}$ meter is sometimes referred to as a "potentiometric $\mathrm{pH}$ meter". The difference in electrical potential relates to the acidity or $\mathrm{pH}$ of the solution[3]. The $\mathrm{pH}$ meter is used in many applications ranging from (fig1.1) experimentation to quality control.

The LM35 is an integrated circuit sensor that can be used to measure temperature with an electrical output proportional to the temperature. The LM35 generates a higher output voltage than thermocouples and may not require that the output voltage be amplified. The LM35 series are 


\section{International Journal of Engineering Applied Sciences and Technology, 2020 \\ Vol. 4, Issue 10, ISSN No. 2455-2143, Pages 321-327 \\ Published Online February 2020 in IJEAST (http://www.ijeast.com)}

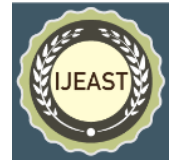

precision integrated-circuit temperature sensors, whose output voltage is linearly proportional to the Celsius (Centigrade) temperature. The LM35 thus has an advantage over linear temperature sensors calibrated in ${ }^{\circ}$ Kelvin, as the user is not required to subtract a large constant voltage from its output to obtain convenient Centigrade scaling. The LM35 does not require any external calibration or trimming to provide typical accuracies of $\pm 1 / 4^{\circ} \mathrm{C}$ at room temperature and $\pm 3 / 4^{\circ} \mathrm{C}$ over a full -55 to $+150^{\circ} \mathrm{C}$ temperature range. Low cost is assured by trimming and calibration at the wafer level. The LM35's low output impedance, linear output, and precise inherent calibration make interfacing to readout or control circuitry especially easy. It can be used with single power supplies, or with plus and minus supplies. As it draws only $60 \mu \mathrm{A}$ from its supply, it has very low self-heating, less than $0.1^{\circ} \mathrm{C}$ in still air.

The LM35 is rated to operate over a $-55^{\circ}$ to $+150^{\circ} \mathrm{C}$ temperature range, while the $\mathrm{LM} 35 \mathrm{C}$ is rated for a $-40^{\circ}$ to $+110^{\circ} \mathrm{C}$ range $\left(-10^{\circ}\right.$ with improved accuracy). The LM35 series is available packaged in hermetic TO-46 transistor packages, while the LM35C, LM35CA, and LM35D are also available in the plastic TO-92 transistor package. The LM35D is also available in an 8-lead surface mount small outline package and a plastic TO-220 package.

A gas detection is a device that detects the presence of gases in an area, often as part of a safety system. This type of equipment is used to detect a gas leak or other emissions and can interface with control system. Gas leak detection is the process of identifying potentially hazardous gas leaks by sensors. Additionally a visual identification can be done using a thermal camera These sensors usually employ an audible alarm to alert people .

The sound sensor module provides an easy way to detect sound and is generally used for detecting sound intensity. This module can be used for security, switch, and monitoring applications. Its accuracy can be easily adjusted for the convenience of usage. dangerous gas has been detected. Exposure to toxic gases can also occur in operations such as painting, fumigation, fuel filling, construction, excavation of contaminated soils, landfill operations, entering confined spaces, etc. Common sensors include combustible gas sensors, photoionization detectors, infrared point sensors, ultrasonic sensors, electrochemical gas sensors, and metal-oxide-semiconductor sensors (MOS sensors).

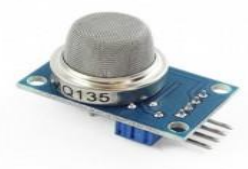

Fig1.2: Gas sensor
More recently, infrared imaging sensors have come into use. All of these sensors are used for a wide range of applications and can be found in industrial plants, refineries, pharmaceutical manufacturing, fumigation facilities, paper pulp mills, aircraft and shipbuilding facilities, hazmat operations, waste-water treatment facilities, vehicles, indoor air quality testing and homes. A control system so a process can be automatically shut down. A gas detector can sound an alarm to operators in the area where the leak is occurring, giving them the opportunity to leave(1.3). This type of device is important because there are many gases that can be harmful to organic life, such as humans or animals.

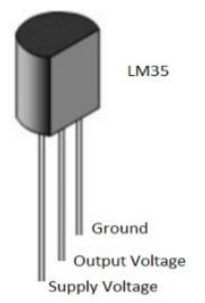

\section{Fig1.3: Temperature sensor}

In electronics, noise is an unwanted disturbance in an electrical signal. Noise generated by electronic devices varies greatly as it is produced by several different effects. In communication system, noise is an error or undesired random disturbance of a useful information signal The noise is a summation of unwanted or disturbing energy from natural and sometimes man-made sources The LM35 is rated to operate over a $-55^{\circ}$ to $+150^{\circ} \mathrm{C}$ temperature range, while the $\mathrm{LM} 35 \mathrm{C}$ is rated for a $-40^{\circ}$ to $+110^{\circ} \mathrm{C}$ range $\left(-10^{\circ}\right.$ with improved accuracy). The LM35 series is available packaged in hermetic TO-46 transistor packages, while the LM35C, LM35CA, and LM35D are also available in the plastic TO-92 transistor package. The LM35D is also available in an 8-lead surface mount small outline package and a plastic TO-220 package.

It uses a microphone which supplies the input to an amplifier, peak detector and buffer. When the sensor detects a sound, it processes an output signal voltage which is sent to a microcontroller then performs necessary processing. The sound sensor module recognizes sound and its force. It utilizes a mouthpiece which supplies the contribution to an intensifier, top identifier and cushion. At the point when the sensor recognizes a sound, it forms a yield flag voltage to a microcontroller. Typical voice sound dimension 19 to $60 \mathrm{~dB}$. Working at $3.3 \mathrm{~V}-5 \mathrm{~V}$. 


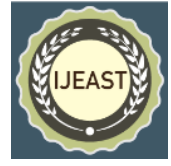

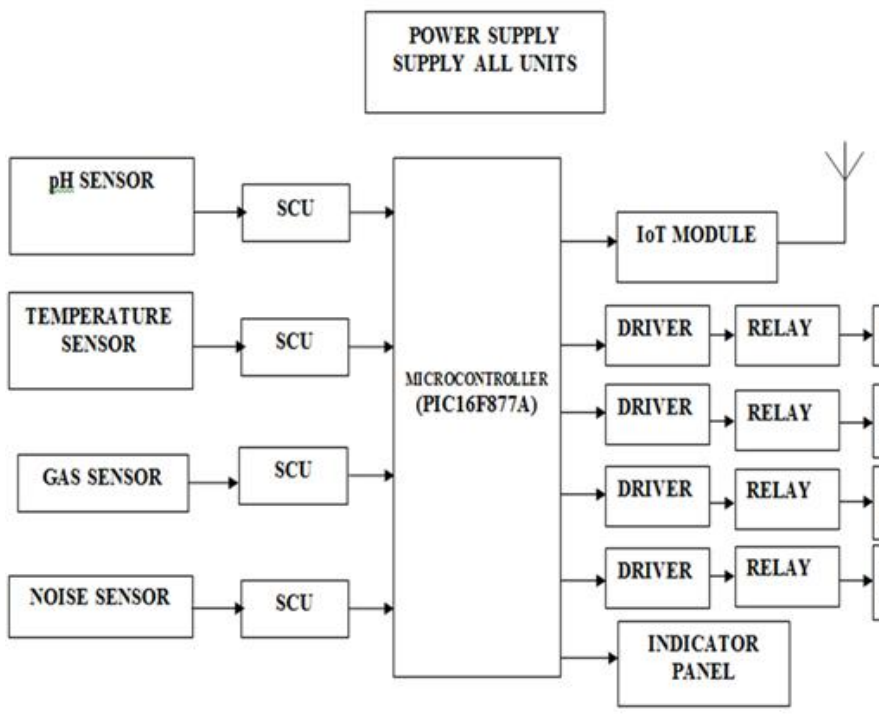

Fig 2: IOT Enabled Industrial Pollution Monitoring System

The block diagram of the operating principle is provided in the above figure. Power supplies for electronic devices can be broadly divided into linear and switching power supplies. The linear supply is a relatively simple design that becomes increasingly bulky and heavy for high current devices; voltage regulation in a linear supply can result in low efficiency. A switched-mode supply of the same rating as a linear supply will be smaller, is usually more efficient, but will be more complex. Power supplies for electronic devices can be broadly divided into linear and switching power supplies. The linear supply is a relatively simple design that becomes increasingly bulky and heavy for high current devices; voltage regulation in a linear supply can result in low efficiency. A switched-mode supply of the same rating as a linear supply will be smaller, is usually more efficient, but will be more complex. Power supplies for electronic devices can be broadly divided into linear and switching power supplies. The linear supply is a relatively simple design that becomes increasingly bulky and heavy for high current devices; voltage regulation in a linear supply can result in low efficiency. A switched-mode supply of the same rating as a linear supply will be smaller, is usually more efficient, but will be more complex.

The voltage produced by an unregulated power supply will vary depending on the load and on variations in the AC supply voltage. For critical electronics applications a linear regulator will be used to stabilize and adjust the voltage. This regulator will also greatly reduce the ripple and noise in the output direct current. Linear regulators often provide current limiting, protecting the power supply and attached circuit from over current. Adjustable linear power supplies are common laboratory and service shop test equipment, allowing the output voltage to be set over a wide range. For example, a bench power supply used by circuit designers may be adjustable up to 30 volts and up to 5 amperes output. Some can be driven by an external signal, for example, for applications requiring a pulsed output.

\section{SYNTHESIS AND TECHNIQUES OF PIC MICROCONTRPLLER} VALVE PIC is a family of Harvard architecture
microcontrollers made by Microchip Technology, derived Efrom the PIC1640. Originally developed by General FHinstruments microelectronics Division. The name PIC Dinitially referred to "programmable interface controller" vepelopers and hobbyists alike due to their low cost, wide 2 sovailability, large user base, extensive collection of application ShPotes, availability of low cost or free development tools, and serial programming (and re-programming with flash memory) capability. Microchip announced on February 2008 the shipment of its six billionth PIC processor. Microcontroller is a general purpose device, which integrates a number of the components of a microprocessor system on to single chip. It has inbuilt CPU, memory and peripherals to make it as a mini computer. The microcontroller that has been used for this project is from PIC series. PIC microcontroller is the first RISC based microcontroller fabricated in CMOS (complementary metal oxide semiconductor) that uses separate bus for instruction and data allowing simultaneous access of program and data memory. The main advantage of CMOS and RISC combination is low power consumption resulting in a very small chip size with a small pin count. The main advantage of CMOS is that has immunity to noise than other fabrication techniques.

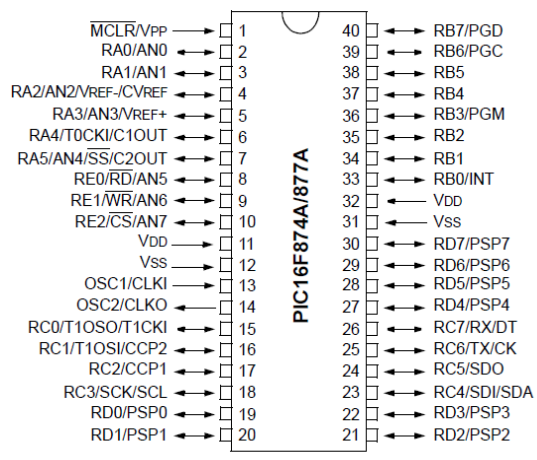

Fig 3: Pin Diagram Of Microcontroller

\section{INTERNET OF THINGS (IOT)}

The Internet of things is the network of physical devices, vehicles, home appliances and other items embedded with electronics, software, sensors, actuators and connectivity which enables these objects to connect and exchange data. Each thing is uniquely identifiable through its 
embedded computing system but is able to inter-operate within the existing Internet infrastructure[7]. The IoT allows objects to be sensed or controlled remotely across existing network infrastructure, creating opportunities for more direct integration of the physical world into computer-based systems, and resulting in improved efficiency, accuracy and economic benefit in addition to reduced human intervention. When IoT is augmented with sensors and actuators, the technology becomes an instance of the more general class of cyberphysical systems, which also encompasses technologies such as smart grids, virtual power plants, smart homes, intelligent transportation and smart cities.

\section{A.SMART HOME}

IOT devices are a part of the larger concept of home automation, also known as domotics . Large smart home systems utilize a main hub or controller to provide users with a central control for all of their devices. These devices can include lighting, heating and air conditioning, media and security systems. Ease of usability is the most immediate benefit to connecting these functionalities[10]. Long term benefits can include the ability to create a more environmentally friendly home by automating some functions such as ensuring lights and electronics are turned off. One of the major obstacles to obtaining smart home technology is the high initial cost.

\section{B.MEDICAL AND HEALTHCARE}

IOT devices can be used to enable remote health monitoring and emergency notification systems. These health monitoring devices can range from blood pressure and heart rate monitors to advanced devices capable of monitoring specialized implants, such as pacemakers, Fitbit electronic wristbands, or advanced hearing aids. Some hospitals have begun implementing "smart beds" that can detect when they are occupied and when a patient is attempting to get up. It can also adjust itself to ensure appropriate pressure and support is applied to the patient without the manual interaction of nurses. According to the latest research, US Department of Health plans[8] to save up to USD 300 billion from the national budget due to medical innovations.

\section{ESP8266-12E NODE MCU(IOT MODULE)}

Node MCU is an open source IOT platform. It includes firmware which runs on the ESP8266 WiFiSoC from Espressif Systems, and hardware which is based on the ESP-12 module. The Internet of things (IOT) is the network of everyday objects - physical things embedded with electronics, software, sensors, and connectivity enabling data exchange. Basically, a little networked computer is attached to a thing, allowing information exchange to and from that thing. Be it light bulbs, toasters, refrigerators, flower pots, watches, fans, planes, trains, automobiles, or anything else around you, a little networked computer can be combined with it to accept input (especially object control) or to gather and generate informational output (typically object status or other sensory data). This means computers will be permeating everything around us - ubiquitous embedded computing devices, uniquely identifiable, interconnected The ESP8266 is a Wi-FiSoC integrated with a Tensilica Xtensa LX106 core, widely used in IOT applications. Node MCU started on 13 Oct 2014, when Hong committed the first file of node mcu-firmware to GitHub. Two months later, the project expanded to include an open-hardware platform when developer Huang R committed the gerber file of an ESP8266 board, named devkit v0.9. Later that month.

\section{ESP8266 ARDUINO CORE}

Arduino began developing new MCU boards based on non-AVR processors like the ARM/SAM MCU and used in the Arduino Due, they needed to modify the Arduino IDE so that it would be relatively easy to change the IDE to support alternate tool chains to allow Arduino $\mathrm{C} / \mathrm{C}++$ to be compiled down to these new processors. They did this with the introduction of the Board Manager and the SAM Core. A "core" is the collection of software components required by the Board Manager and the Arduino IDE to compile an Arduino $\mathrm{C} / \mathrm{C}++$ source file down to the target MCU's machine language. Some creative ESP8266 enthusiasts have developed an Arduino core for the ESP8266 WiFi SoC that is available at the GitHub ESP8266 Core webpage. This is what is popularly called the "ESP8266 Core for the Arduino IDE" and it has become one of the leading software development platforms for the various ESP8266 based modules and development boards, including NodeMCUs.

\section{E. NODE USB}

Node USB is an open IOT platform about the size of a standard USB stick. It was designed to leverage Node MCU (Lua) for easy programming and has the extra feature of USB capability. It is ideal for Plug-n-Play solutions, allowing easy prototyping for developers. Node MCU provides access to the GPIO (General Purpose Input/Output.

Fig 2.1: GPIO For Pin Mapping Table 


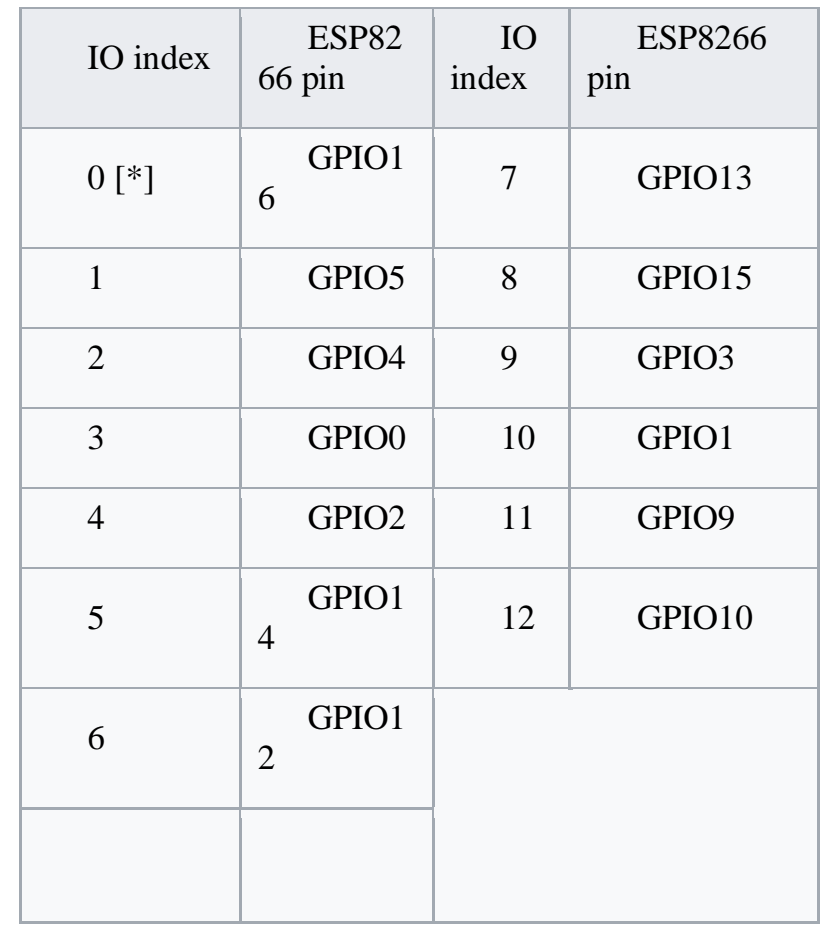

Node MCU is an open source IOT platform based on the ESP-12E module. The version 1.0 is the 5th design of Node MCU devkit. This uses CP2102 as UART bridge, and can flash firmware automatically by using nodemcu-flasher. Also it has a voltage regulator to convert from $5 \mathrm{v}$ to $3.3 \mathrm{v}$ which is the required by the esp21e moduleut) and for developing purposes below pin mapping table should be referenced.

\section{SOLENOID VALVE}

A Solenoid valve is an en electrochemical valve for use with liquid or gas. The valve is controlled by a electric current through a solenoid coil. solenoid valves may have two or more ports. In case of a three port valve, the outflow is switched between the outlet ports. Multiple solenoid valve can be placed together on a manifold. solenoid valve are the most frequently used control elements in fluidics. There tasks are to shutoff, release, dose, distribute or mix fluids[15]. They are found in many application areas. Solenoids offer fast and safe switching high reliability, long service life, good medium compatibility of the materials used, low control power and compatibility of the materials used, low control power and compact design. Besides the plunger-type actuator which is used most frequently, pivoted-armature actuators and rocker actuators are also used. As it relates to compressed air valves, a solenoid is a device that, when energized with electricity, creates a magnet inside itself that moves something. Depending on the type of air valve, the item that moves could be a device to control air flow through the valve, or a device to control air flow within the solenoid to do work. More on this later.

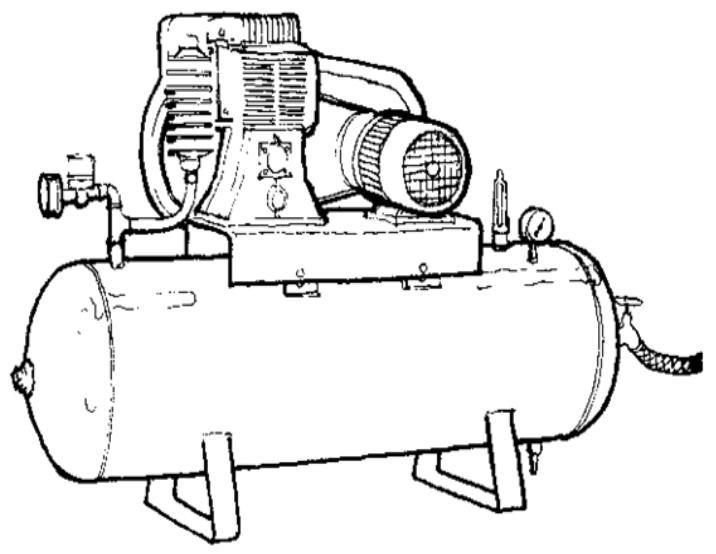

Fig 3: Direction Control Valve

Directional Control Valves can be used to provide a number of different functions. They can:

a. Control the direction of cylinder movement

b. Select the path air takes through the system

c. Perform logic control functions

d. Stop and start air flow (on-off valves)

e. Sense cylinder positions (limit valves)

Directional Control valves are classified according to a number of design characteristics:

a. The internal valve mechanism (i.e. 'poppet' or 'sliding spool')

b. The number of switching positions (usually 2 or 3 )

c. The number of connecting ports (i.e. 3 or 5 port)

d. The method of valve actuation ( i.e. lever, roller, plunger)

\section{CONCLUSION}

In this work, we have proposed a unique model for future IOT-based healthcare systems, which can be applied to both general systems and systems that monitor specific conditions. The IOT concept can be applied to a wide range of application. We implemented the use of IOT in Industrial pollution monitoring and this project, real time air pollution monitoring system based on IOT is presented. GSM is connected through level converter and an IOT module is connected to get the real time data so that the users can login and get data. Real time monitoring of air quality parameters ensures that the industrial emissions levels are maintained 


\section{International Journal of Engineering Applied Sciences and Technology, 2020 \\ Vol. 4, Issue 10, ISSN No. 2455-2143, Pages 321-327 \\ Published Online February 2020 in IJEAST (http://www.ijeast.com)}

throughout and helps us to track all the data in a single place. The implementation cost is very economical as the sensors and the microcontrollers are easily available.

\section{REFERENCE}

[1]RumaGosh; Julian W.Gardner; Prasanta kumar Guha"Air pollution monitoring using near room temperature resistive gas sensors: A Review" (Aug 2019) DOI:10.1109/TED.2019.2924112,IEEE.

[2] Saha.H.N., Auddy.s., chatterjee.A., Pal.S., Pandey.S., singh.R., Singh.R.,Sharan.P., Banarjee.s., Ghosh.D., and Maity.A.(2017),'pollution control using internet of things(IOT)', Vol.10,pp,65-68.

[3]D. Chen and Y. J. Yuan, "Thin-film sensors for detection of formaldehyde: A review," IEEE Sensors J., vol. 15, no. 12, pp. 6749-6760, Dec. 2015.

[4]J. M. Smulko, "New approaches for improving selectivity and sensitivity of resistive gas sensors: A review," Sensor Rev., vol. 35, no. 4, pp. 340-347, 2015.

[5]R. K. Jha, D. Burman, S. Santra, and P. Guha, "WS2/GO nanohybrids for enhanced relative humidity sensing at room temperature," IEEE Sensors J., vol. 17, no. 22, pp. 7340-7347, 2017.

[6] X. Zhang et al., "SnS2 nanoflakes anchored graphene obtained by liquid phase exfoliation and MoS2 nanosheet composites as lithium and sodium battery anodes," Electrochim. Acta, vol. 227, pp. 203-209, Feb. 2017.

[7] Y. J. Fan, Y. H. Yin, L. D. Xu, Y. Zeng, and F. Wu, "IoT-based smart rehabilitation system," IEEE Transactionson Industrial Informatics, vol. 10, no. 2, pp. 1568-1577,2014.

[8] S. Sarkar and S. Misra, "From Micro to Nano: TheEvolution of Wireless Sensor-Based Health Care," IEEEPulse, vol. 7, no. 1, pp. 21-25, 2016.

[9] Y. YIN, Y. Zeng, X. Chen, and Y. Fan, "The internetof things in healthcare: An overview," Journal ofIndustrial Information Integration, vol. 1, pp. 3-13, 32016.

[10]M. N. Azni et al., "Home automation system with android application," 2016 3rd International Conference on Electronic Design (ICED), Phuket, 2016, pp. 299-303.

[11]C.A.Howedi and A. Jwaid, "Design and implementation prototype of a smart house system at low cost and multi-functional," 2016 Future Technologies Conference (FTC), San Francisco, CA, 2016, pp. 876-884.

[12]R. Kazi and G. Tiwari, "IoT based Interactive Industrial Home wireless system, Energy management system and embedded data acquisition system to display on web page using GPRS, SMS \& E-mail alert," 2015 International
Conference on Energy Systems and Applications, Pune, 2015, pp. 290-295.

[13]Mile Mrinal and Lakade Priyanka, Mashayak Saniya , Katkar Poonam and A.B. Gavali," Smart Home - Automation and Security System Based on Sensing Mechanism" ISBN.978-1-5090-3239- 6/17/\$31.00@2017IEEE.

[14] Chaudhari. A.N., and Kulkarni. G.A. (2017), 'IoT based Environmenal Pollution Monitoring System', IRJET. Vol. 04 , pp. 1823-1829.

[15]Saha. H.N., Auddy. S., Chatterjee. A., Pal. S., Pandey. S., Singh. R., Singh. R., Sharan. P., Banarjee. S., Ghosh. D., and Maity. A. (2017), 'Pollution Control using Internet of Things (IoT)’, Vol. 10 ,pp. 65-68. 